Knowledge sharing intention at Malaysian higher learning institutions: The academics' viewpoint

\author{
Muhammad Ashraf Fauzi \\ Multimedia University, Malaysia \\ International Islamic University Malaysia, Malaysia \\ Christine Nya-Ling Tan \\ Multimedia University, Malaysia \\ T. Ramayah \\ Universiti Sains Malaysia, Minden, 11800 Penang, Malaysia
}

Universiti Malaysia Sarawak, 94300 Kota Samarahan, Sarawak, Malaysia

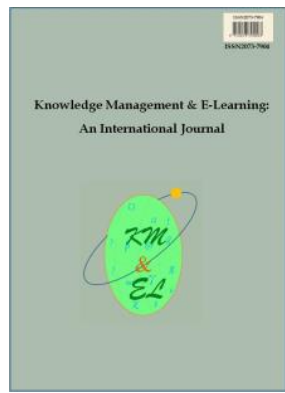

Knowledge Management \& E-Learning: An International Journal (KM\&EL) ISSN 2073-7904

Recommended citation:

Fauzi, M. A., Tan, C. N. L., \& Ramayah, T. (2018). Knowledge sharing intention at Malaysian higher learning institutions: The academics' viewpoint. Knowledge Management \& E-Learning, 10(2), 163-176. 


\title{
Knowledge sharing intention at Malaysian higher learning institutions: The academics' viewpoint
}

\author{
Muhammad Ashraf Fauzi* \\ Faculty of Management \\ Multimedia University, Malaysia \\ Centre Foundation Studies \\ International Islamic University Malaysia, Malaysia \\ E-mail: ashrafauzi@gmail.com
}

\section{Christine Nya-Ling Tan}

Faculty of Management

Multimedia University, Malaysia

E-mail: nltan@mmu.edu.my

\section{T. Ramayah}

School of Management

Universiti Sains Malaysia, Minden, 11800 Penang, Malaysia

Faculty of Cognitive Science and Human Development

Universiti Malaysia Sarawak, 94300 Kota Samarahan, Sarawak, Malaysia

E-mail: ramayah@usm.my

*Corresponding author

\begin{abstract}
Knowledge sharing (KS) is a culture that has been fostered and supported in higher learning institutions (HLIs) in Malaysian. This research applies Theory of Planned Behavior (TPB) and Social Capital Theory (SCT) to determine the factors associated with Malaysian academic's KS intention in HLIs. The results indicate that social networking is an important factor of academics' attitude to KS, while commitment and trust do not influence their attitude to KS. Using social media is found to be a significant factor of perceived behavioral control towards KS. Further, academics' attitude to KS and perceived behavioral control towards $\mathrm{KS}$ are found to be significant determinants of their KS intention, while management support for subjective norm of KS is not significant for KS intention.
\end{abstract}

Keywords: Knowledge sharing; Higher learning institutions; Theory of planned behavior; Social capital theory; Malaysia

Biographical notes: Muhammad Ashraf Fauzi is a Phd student at Faculty of Management, Multimedia University. He also a Matriculation lecturer in Centre for Foundation Studies International Islamic University Malaysia.

Christine Nya-Ling Tan is a senior lecturer at Multimedia University Malaysia.

T. Ramayah is currently a Professor of Technology Management at the School of Management, Universiti Sains Malaysia, Visiting Professor King Saud 
University, Kingdom of Saudi Arabia, Universiti Malaysia Sarawak (UNIMAS) and Universiti Teknologi Malaysia (UTM), Adjunct Professor at Sunway University, Multimedia University (MMU) and Universiti Tenaga Nasional (UNITEN), Malaysia. His publications have appeared in Information \& Management, International Journal of Operations \& Production Management, Tourism Management, Journal of Travel Research, International Journal of Contemporary Hospitality Management, Journal of Environmental Management, Technovation, International Journal of Information Management, Safety Science, Industrial Management and Data Systems, Social Indicators Research, Quantity \& Quality, Service Business, Knowledge Management Research \& Practice, Journal of Medical System, International Journal of Production Economics, Personnel Review, and Telematics and Informatics among others. His full profile can be accessed from http://www.ramayah.com

\section{Introduction}

In higher learning institutions (HLI), knowledge management (KM) is important in creating, acquiring, disseminating and leveraging knowledge for attaining competitive advantage and the institution's objectives (Nicolas, 2004; Suhaimee, Zaki, Bakar, \& Alias, 2006). Among the elements of KM, knowledge sharing (KS) is regarded as the most important ( $\mathrm{Yu}, \mathrm{Lu}, \& \mathrm{Liu}, 2010)$. Academics are the pillars of KS, constantly disseminate knowledge to their students and peers in HLIs. Knowledge in HLIs is intensive because it is created from new research and studies and is further documented in publications (Fullwood, Rowley, \& Delbridge, 2013). Apart from research, teaching and other duties such as community service are considered core duties of academics. In HLIs, the problem of KS is that some academics are reluctant to share their research findings which may be useful for various issues and contexts. Therefore, this study aims to identify the determinants of academics' KS intention including individual (i.e. commitment, social network and trust), organizational (i.e. management support) and technological factors (i.e. social media).

\subsection{Research background}

The main theories adapted for this study are the Theory of Planned Behavior (TPB) and the Social Capital Theory (SCT). TPB serves as a foundation for explaining the behavior of academics in KS (Roberto, Shafer, \& Marmo, 2014). It proposes that human behavior may be determined by attitudes, subjective norms and perceived behavioral control (PBC) (Ajzen 1991). Attitudes are the individual's traits which are formed by certain characteristics. On the other hand, subjective norm is the person's belief of what other people think of him/her. Meanwhile, PBC is the person's perception that they have control over their actions. Empirical evidence shows that a correlation exists between PBC and behavioral intention. Studies show that the intention to act a behavior is directly proportional to their PBC.

SCT provides strong theoretical support for the individual determinants of academics' KS intention, including trust and social networking. SCT is effective in explaining individuals' and groups' well-being (Bassani, 2007). Putnam (1995) explains that SCT relates to the social aspect of life, including trust and networking which require individuals to work together in an effective manner in order to achieve common goals. Social interaction serves as platform for testing these SCT variables. Trust and social 
networking in academia are crucial, as the education sector needs academics to work together to achieve common goals (Putnam, 1995).

\subsection{Hypotheses development and theoretical framework}

\section{Commitment}

Committed employees are the dream of every employer. As for HLIs, having committed personnel will ensure the prosperity of their institutions. According to Meyer and Parfyonova (2010), employees' commitment to their jobs will lead the HLI towards gaining competitive advantage. Academics' attitudes depend on the willingness to commit, which is a serious workplace concern. When academics are committed, a culture of KS can easily spread in HLIs. In order to encourage academics to voluntarily commit to sharing knowledge, senior management should seek the best available engagement methods. Apart from that, commitment in the workplace can affect employees' level of effort and leads to absenteeism and job turnover (Joiner \& Bakalis, 2006). Thus, the first hypothesis is:

H1: Commitment has a positive effect on academics' attitudes toward knowledge sharing

\section{Social network}

Social network has been proven to have significant factor for employees' intention to share in the workplace (Chow \& Chan, 2008). A person, who has more connection via friends and associates, will have the tendency to exchange ideas, thoughts and passion. This relationship therefore is suggested as the main predictors for job satisfaction which can directly promotes KS activities (Lacy \& Sheehan, 1997). The wider connections amongst academics within and outside their workplace would make KS much easier and able to reach more people. Good relationship among academics also will ensure knowledge disseminated more efficiently. Academics networking among themselves in a HLI, will have positive effects on the attitude and subjective towards KS. When two people have a good relationship, it will create a comfortable situation where knowledge can be shared between them. Community of practice (COP)is formed with emotional bonding and thus can enhance KS. Therefore, the next hypothesis is:

\section{H2: Social networks have a positive effect on academics' knowledge sharing}

Trust

In the context of KS, trust is the dimension that most researchers focused on (Wang \& Noe, 2010). When trust exists among academics, it motivates them to work as a team to achieve common goal and vision. By fostering trust, healthy relationships could be created. Jolaee, Md Nor, Khani, and Md Yusoff (2014) suggest that without trust, relationship among academics cannot be effective for knowledge to be shared. When information is personal and confidential, he or she would not share it to others except for those they trust. Therefore, to foster the trust among academics, trust must exist to avoid misuse of the knowledge. The top management needs to discover ways and intends to urge the trustworthiness to be ingrained among academics in respective HLIs. It is paramount that trust can be made available among academics so that their KS intentions could be enhanced, rather than forcing them to share their knowledge. The third hypothesis is therefore posited:

H3: Trust has a positive effect on academics' intention toward knowledge sharing 


\section{Management Support}

Every employee would appreciate the support given by their immediate supervisors. In the context of HLIs, the top management plays a crucial role in enhancing KS among academics. The supports include direct participation of top management in programs and activities related to knowledge attribution, and appreciating the work and effort of academics in KS. Academics will give their full support when they fully understand the importance of KS, which in return, will ensure voluntary participation (Kang, Kim, \& Chang, 2008). The top management has a role in ensuring that academics understand and realize that they are supporting the KS initiatives by the academics. Hence, this will convince and able to make them share voluntarily their expertise and knowledge (Tan \& Md. Noor, 2013). The next hypothesis is:

H4: Management support has a positive effect on academics' subjective norm towards knowledge sharing

\section{Social Media}

Keeping up with recent technological advancement is a must for academics. Without knowing the latest development, they risk of being left behind in new research and knowledge. Social media, being the tool for keeping up to date, can make academics share what they know without much effort and time waste (Osatuyi, 2013). By engaging with social media, academics can communicate and have channels of networking among other scholars within and outside their HLI and also students from other HLIs. Examples of social media in the market that can be utilized academics to share are Facebook, Twitter and LinkedIn among others. Fast advancement of technology has spearheaded on gadget technology. Computers, mobile phones, tablets and other software are in progress with social media applications. Academics should find ways to learn and adapt to these new social media platforms to make sure that KS activities can be developed. The fifth hypothesis is:

H5: Social media use has a positive effect on academics' perceived behavioral control toward knowledge sharing

\section{Attitude toward $K S$}

Attitude, one of the major predictors for intention, is known as the degree of a person evaluation favoring to a specific behavior (Ajzen, 1991). Academics who have favorable attitude towards KS, would share their knowledge freely in a HLI. Therefore, it is important to develop and instill this KS attitude among academics. Hypothesis 6 is therefore:

\section{H6: Attitude has a positive effect on academics' intention to share knowledge}

\section{Subjective norm}

Another factor that determines an individual's intention is subjective norm. In the context of HLIs, subjective norm is defined as the perception of other parties towards academics' KS behavior. This includes top management, colleagues and students. It relies on normative belief of the individual, the belief of what others might think of academics with their KS behavior (Lai, Chen, \& Chang, 2014). If sharing knowledge in a community is a norm, academics are expected to also share their knowledge. Community will view that academics are selfish people if they did not share, while others are. This perceived perception of others will urge academics to share their knowledge, of which when in the case they do not share, they might think others have bad perception on them (Goh \& Sandhu, 2013). Thus, hypothesis 7 is: 
H7: Subjective norm has a positive effect on academics' intention to share knowledge Perceived behavioral control (PCB)

When an action is perceived as difficult, or when academics think that an action is hard to perform, they will not do it. PBC is the perception of individual on the effort to act a behavior, whether it is doable or not (Ajzen \& Madden, 1986). If KS are effortless or require little effort, academics would be easily engaged to it, creating more chances of KS to happen. Previous studies have proven that PBC is one of the strongest predictors of behavior (Manstead \& Van Eekelen, 1998). Academics who have control on their belief system will give their full effort for KS, even though when they face hardship along the way of in sharing. The last hypothesis is:

H8: Perceived behavioral control has a positive effect on academics' intention to share knowledge

\section{Research methodology}

\subsection{Sampling and data collection}

This research applies quota sampling to three sub-groups. Professors, associate professors and senior lecturers were divided evenly among the sub-groups to 30:40:40. All the respondents are from a public HLI. 399 surveys were sent to potential respondents. The returns were 45 responses, which yield a rate of response of 11.2 percent.

\subsection{Measurement}

All the items in the survey are adapted from previously validated studies. Items for commitment are taken from Allen and Meyer (1990), social network are from Kim and Lee (2006), trust are from Mcallister (1995), management support items are from Sveiby and Simons (2002), social media are from Thong, Hong, and Tam (2002), attitude, subjective norm and intention come from Bock, Zmud, Kim, and Lee (2005) while items for perceived behavioral control are taken from Wu and Chen (2005). 7-point Likert scale is applied in this study. Range of the scale are from 1 to 7 , strongly disagree to strongly agree respectively. The accuracy of 7-point Likert scale in social science studies has proven in measuring true evaluation of respondent (Finstad, 2010). 7-point scale also covers the information on theory and approaches in metric for optimal respondent response. The survey was sent for a time period of one month, directly answered through email (Cox, 1980).

\section{Result and data analysis}

\subsection{Analysis method}

Partial least square structural equation modeling (PLS-SEM) is applied in this study's analysis by using Smart PLS version 2.0. PLS-SEM is better than other methods based on several justifications. Firstly, it performs variable selections automatically. Secondly, it has diverse classification tasks. It is also statistically efficient, and finally, it has fast computational process (Boulesteix \& Strimmer, 2006). 


\subsection{Descriptive statistics}

A total of 45 responses were received from all the three sub-groups of professor, associate professor and senior lecturers with evenly distributed gender of 22 males and 23 females. In term of races, Malay academics amount to $75.6 \%$, Chinese, Indian and others at $8.9 \%, 4.4 \%$ and $11.1 \%$ respectively. Only one respondent has a Master's degree while others have $\mathrm{PhD}$. The number of years working in academics ranges from 1-5 years having 5 respondents, with respondent having years of working of more than 26 years and above with $11.1 \%$.

\subsection{Measurement model}

PLS-SEM applies two stages model, namely measurement model and structural model. Measurement model measures the latent variable or the construct that is applied in a particular study. It addresses the items' reliability and validity, focusing on the construct in a model. Chin (2010) asserts that measurement model would facilitate researchers to identify the validity of the items convergent and discriminant respectively. Items must diverse or known as converged with each other. Items must correspond to their own construct to show that they are in agreement. While for the same construct, two or more items should be varied with each other (Bagozzi, Yi, \& Phillips, 1991). Table 1 shows the descriptive analysis of the respondents.

Table 1

Descriptive statistics

\begin{tabular}{|c|c|c|c|}
\hline Measure & Items & Frequency & Percentage \\
\hline \multirow{2}{*}{ Gender } & Male & 22 & 48.9 \\
\hline & Female & 23 & 51.1 \\
\hline \multirow{4}{*}{ Race } & Malay & 34 & 75.6 \\
\hline & Chinese & 4 & 8.9 \\
\hline & Indian & 2 & 4.4 \\
\hline & Others & 5 & 11.1 \\
\hline \multirow{2}{*}{ Qualification } & $\mathrm{PhD}$ & 44 & 97.8 \\
\hline & Masters & 1 & 2.2 \\
\hline \multirow{3}{*}{ Position } & Professor & 10 & 22.2 \\
\hline & Associate Professor & 10 & 22.2 \\
\hline & Senior Lecturer & 25 & 55.6 \\
\hline \multirow{6}{*}{$\begin{array}{l}\text { Years of } \\
\text { working }\end{array}$} & $1-5$ & 5 & 11.1 \\
\hline & $6-10$ & 9 & 20.0 \\
\hline & $11-15$ & 12 & 26.7 \\
\hline & $16-20$ & 9 & 20.0 \\
\hline & $21-25$ & 5 & 11.1 \\
\hline & 26 and above & 5 & 11.1 \\
\hline
\end{tabular}


Convergent validity test of the items shows that all the items are loaded highly on their construct which indicates the validity. Average variance extracted (AVE) and composite reliability (CR) are indications of reliability and the value must exceed 0.50 and 0.70 respectively (Chin, 2010; Fornell \& Larcker, 1981; Hair Jr, Sarstedt, Hopkins, \& Kuppelwieser, 2014). As shown in Table 2, the AVE ranges from 0.6083 to 0.8281 , while the CR ranges from 0.8602 to 0.960 . This can be concluded that all the items reliability met the threshold value.

Using Fornell and Larcker (1981) criterion, discriminant validity is tested. All the items are loaded on the assigned construct with the indication of the square root of the AVE (Gefen, Straub, \& Boudreau, 2000, Voorhees, Brady, Calantone, \& Ramirez, 2016). The square root of AVE is shown in Table 2 where all the values are higher than the correlation values of other variables. This indicates satisfactory discriminant validity of the construct and its items.

Table 2

Discriminant validity

\begin{tabular}{|c|c|c|c|c|c|c|c|c|c|}
\hline & $\mathbf{A T}$ & $\mathrm{CO}$ & IN & MS & PBC & SM & $\mathbf{S N}$ & SU & TR \\
\hline AT & 0.874 & & & & & & & & \\
\hline $\mathrm{CO}$ & 0.468 & 0.843 & & & & & & & \\
\hline IN & 0.638 & 0.341 & 0.881 & & & & & & \\
\hline MS & 0.349 & 0.823 & 0.398 & 0.884 & & & & & \\
\hline PBC & 0.572 & 0.454 & 0.837 & 0.485 & 0.910 & & & & \\
\hline SM & 0.469 & 0.359 & 0.449 & 0.326 & 0.627 & 0.830 & & & \\
\hline SN & 0.572 & 0.712 & 0.36 & 0.559 & 0.502 & 0.542 & 0.779 & & \\
\hline SU & 0.666 & 0.426 & 0.645 & 0.514 & 0.622 & 0.294 & 0.398 & 0.781 & \\
\hline TR & 0.399 & 0.670 & 0.370 & 0.537 & 0.489 & 0.38 & 0.692 & 0.254 & 0.872 \\
\hline
\end{tabular}

Note. AT=Attitude, $\mathrm{CO}=$ Commitment, $\mathrm{IN}=$ Intention, $\mathrm{MS}=$ Management support, $\mathrm{PBC}=\mathrm{Perceived}$ behavioral control, $\mathrm{SM}=$ Social media, $\mathrm{SN}=$ Social network, $\mathrm{SU}=$ Subjective norm, $\mathrm{TR}=$ trust

\subsection{Structural model}

Structural model is the second part of PLS-SEM analysis. By applying bootstrapping procedure with 5000 samples, the hypothesis can be determined by the path coefficient. Fig. 1 shows the study structural model.

\section{Discussion}

The objectives of this study are to identify the factors that can potentially determine academics' KS intention in HLIs. From the result, the three main factors are TPB, attitude and PBC, while subjective norm is not. Meanwhile, the three KS determinants, it is found that only social network is significant while commitment and trust are not. As for management support, the result has shown a significant effect on subjective norm. Social media, as on the other hand, is significant factor for PBC. 


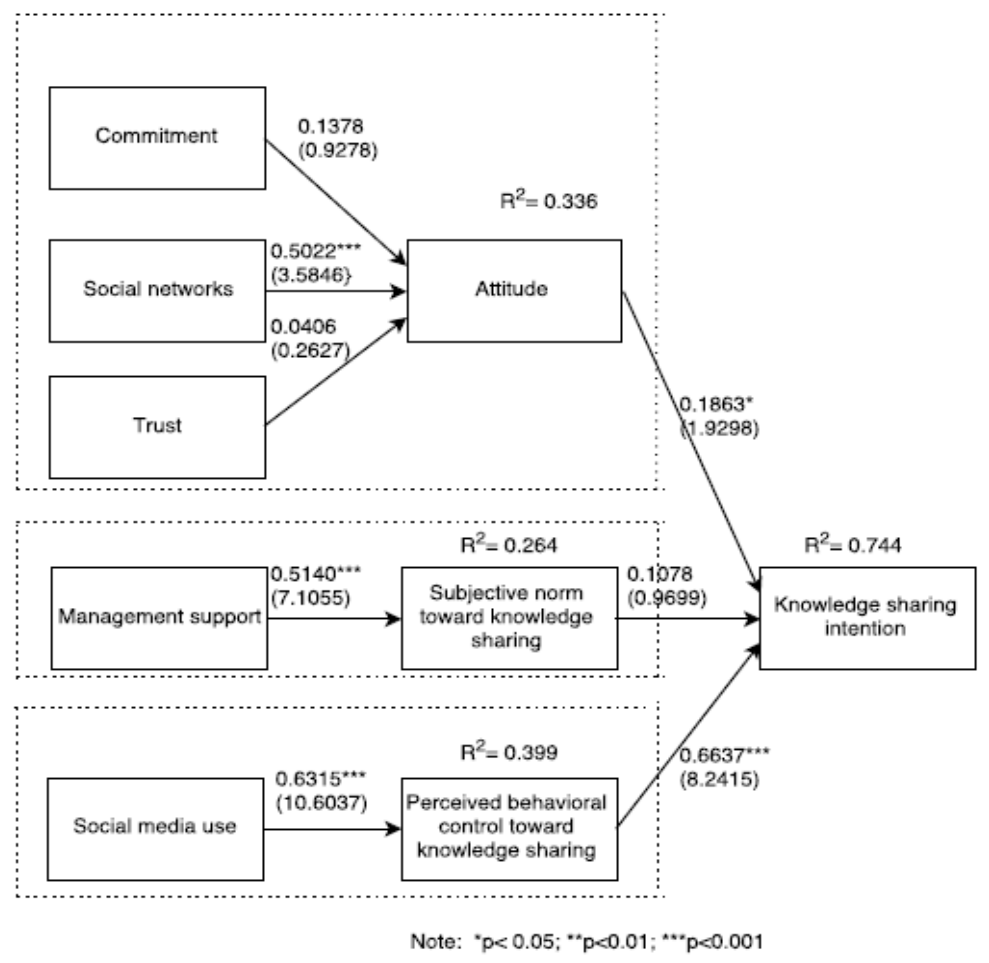

Fig. 1. Structural model

HLIs in the new millennium have been burdened with uphill task in the new era of education landscape. Apart from teaching, academics have to do research, engage in consultation work and up to extend do administration work to meet the demands of their HLI. These tasks are academics' obligation to deliver for the country's overall development including the uphill task of maintaining a high rank in the world's top university ranking such as Times Higher Education and QS (Quacquarelli Symonds). To achieve high ranking worldwide, academics have to focus not only the core duties, but also other work that can contribute to the ranking.

As for the determinants of KS intention, only social network is significant while commitment and trust are not. It can be said that academics have substantial network among their community of expertise and research area, within as well as outside of the HLI that they are working with. More connections with other academics either in the same field for interdisciplinary would strengthen the networking of academics, thus indirectly have a profound effect on KS. Previous study has shown that social network has significant impact on KS intention (Jolaee et al., 2014). Surprisingly, commitment has no significant effect on academics' KS intention. One probable reason for this is that all the respondents are from a public HLI. Compared to academics from private HLIs, academics in public HLIs tend to have low commitment due to the nature of public service where their status and placement in a public HLI are secured regardless of whether they achieved their annual key performance index (KPI) or not. Trust also has no significant effect on academics' KS attitude. Despite being an important predictor for academics' KS, this study shows that Malaysian academics are lacking in trust among each other. Previous studies have supported this claim (see Jolaee et al., 2014; Kim \& Ju, 2008; Chong, Yuen, \& Gan, 2014). This can be explained by the individualistic of the 
Malaysian education system, where every academic must fight for their achievements. The notion of their knowledge being shared might jeopardize their position in the institution.

Attitude of the academics contributes the most to $\mathrm{KS}$ intention with path coefficient of 0.1863 . Attitude is formed within an individual, on which dominantly affecting the KS intention. Having more positive attitude, will make academics more incline to share their knowledge. This finding is consistent with some other studies, which shows that attitude is a significant factor for KS intention (Ramayah, Yeap, \& Ignatius, 2013; Jolaee et al., 2014; Akhavan, Hosseini, Abbasi, \& Manteghi, 2015).

Academics' social media use in this study is found to be significant towards PBC, with the biggest path coefficient of 0.6315 . Even though technology is rapidly moving at a greater acceleration, academics are not left out, in following the current trends and changes. The crucial of KS sets in the platform of social media where academics should utilize the tools available to share and also acquire new knowledge related to their expertise from other experts worldwide. This is supported by a study done by Bhagwatwar, Hara, and Ynalvez (2013).

Among the three TPB constructs, PBC has the strongest influence towards KS intention with path coefficient of 0.6637. It is expected that PBC would have a strong impact on KS intention due to the fact that academics are in control of their behavior. Academic are independent where they can control their actions towards their own behavior.

Management support is also a significant predictor towards academic KS intention. The result demonstrated that academics expect the top management to support them in their career. Management that has strong support can have positive effect on academics to share knowledge willingly. Past studies have shown that management support has significant effect on KS intention (Lin, 2007).

Subjective norm, another construct of the TPB, was found to be insignificant. Academics are not affected by the view of others in their pursuit of KS in a HLI. It is likely that academics are independent in their work, thus what others think of them in sharing what they know does not matter, as what matters is that they are doing is right within their own perspective and understanding. Another explanation that may be possible is that academics seldom meet top manager of their HLI for example the vice chancellor or rector. The highest management they probably meet is head of department, which does not have that much power in determining policy or make important decision for a particular HLI. Therefore, it leads to less meeting between academics and top management which result in academics not knowing what is really wanted by the management.

\section{Implications and conclusion}

\subsection{Theoretical implications}

Theoretically, this study has shed some light on the KS intention of academics in a Malaysian HLI. First and foremost, this study has proposed an integrative model of KS among academics in HLIs. It consists of factors for social psychological of Malaysian academics (commitment, social network and trust), factors for organizational of management support and factor for technological of social media use. It was found that 
the most significant factor for KS intention is PBC. An academic's beliefs that he/she is able to control or withhold his/her action which was found that this behavior has direct impact on the intention. The self-belief within academics corresponds to their use of the social media. When they know and follow the trend on social media, they are more inclined to share, as compared to those who are incapable to use social media and not up to date with current development.

Secondly, the integration of TPB and SCT in this study contributes to the theoretical underpinnings. The two well-known theories are related to the independent and dependent construct available and contribute to the current body of knowledge. By classifying commitment, social network and trust as determinants of attitude, a holistic model could be formed. Determinant of organizational factors is classified into management support while factor for technological is classified into social media. All these determinants specify the platform for those who are involved in a HLI, including the stakeholders and community by identifying the relevant academics' KS intention and what impact it can make on Malaysian education system and South East Asian region as a whole.

\subsection{Practical implications}

Several practical implications can be deduced from this study especially on the management of HLIs. This study provides suggestions by establishing a platform to identify the three main factors that can affect academics' KS intention, which are individual, organization and technology. The issues of hiring academics can be taken from this study output where the cost of hiring new academics is costly. Millions of Ringgit from the government funds have to be spent on academia especially to hire experts in a particular field. It will be a burden if hiring academics at high cost, but they are not willing to share their knowledge and expertise. The taxpayer's money can be saved by understanding the factors that can contribute to academics' KS. In some developing countries, if a position being made vacant by a permanent staff, the administration took a safe step by appointing contract staff, before appointing them permanently (Chudgar, Chandra, \& Razzaque, 2014). HLIs need to hire future academics that have track records of openly involved in KS activities and programs. Therefore, consideration of individual, organizational and technological when an institution wants to appoint new academic staff is important so that the appointment can contribute in $\mathrm{KS}$ activities.

Secondly, the impact of social network on attitudes determinants towards KS intention. It was found that social network was the most significant factor for academics' KS. Serious consideration should be considered by managers of HLIs and the Education Ministry into employing a suitable mechanism to enhance and promote social networking for the sake of KS in HLIs. This can be implemented by adding points for promotion and annual appraisal looking into the frequencies of collaboration and networking within and outside the HLI, either among academics or industrial experts. Rewards or grants can be awarded to academics who able to acquire external projects or consultation work. This demonstrates the broad networking and relationship of academics in building an impactful practice of their expertise via social network.

Another finding from this study is the role of the management in influencing academics to share their knowledge. Top management should know the reality of the academicians' responsibilities and duties, by deeply understanding the roles of academics. By understanding the roles of academics, top managers of each HLI could work together with academics to achieve the nation's educational goals. Solutions need to 
be offered to academics to fulfill the annual research target requirements, so that KS could be encouraged. The practical way to adapt this is by setting a special rubric as an annual performance index. It has not been realized in the current educational context in Malaysia, and ASEAN as a whole. Management also should be opened to criticism, and acknowledge where there are flaws than can be corrected. As experts in their field, academics are limited in solving the problems practically when bureaucracy and politics take over. Knowledge and education should be free from any involvement of any practice that might jeopardize its existence.

\subsection{Conclusion}

Several conclusions can be deduced from this study. Firstly, this study has managed to determine the factors for academics' KS intention through TPB and SCT. The integration of these two theories has contributed to the body of knowledge. Intention is depending on several factors (individual, organizational and technological). Research hypotheses were tested using PLS-SEM as the variance- based method in structural equation modeling. Results indicate that for attitude of academic factor, the only significant determinant is social network, while commitment and trust are not significant. Management support as the factor for subjective norm is significant and social media as the factor for PBC is also significant. Determinants for intention concluded that attitude and PBC are significant, while subjective norm surprisingly is not significant. The main contribution of this study would entitle stakeholders and the Malaysian government as a whole in attaining new and current academics to be participative in KS matters in HLIs. Having academics that are not only knowledge cautious, but also sharing cautious would benefit the country in producing quality research and develop the HLI to a well-known and reputable institution worldwide.

Limitation of this study is that, the data are collected only from one public HLI in Malaysia. The entire private HLI was excluded. Secondly the sample size of 45 respondents is relatively low for generalization. Despite that, this low sample size is enough, due this pilot study of which according to Hertzog (2008), that a pilot study should have at least $10 \%$ of the required full data sample. This is for a suitability of instrument and obtaining estimation for larger study. Further study on other factors that can have significant effects on academics' intention toward KS should be tested. Further studies should incorporate other factors that can relate to academics' KS behavior such as firm innovation capability (Hussein, Singh, Farouk, \& Sohal, 2016), innovative performance (Donate \& de Pablo, 2015).

\section{Acknowledgements}

The author would like to thank the Ministry of Education (MOE) for funding this research this research under the Fundamental Research Grant Scheme (FRGS).

\section{References}

Ajzen, I. (1991). The theory of planned behavior. Organizational Behavior and Human Decision Processes, 50(2), 179-211.

Ajzen, I., \& Madden, T. J. (1986). Prediction of goal-directed behaviour: Attitudes, intentions and perceived behavioural control. Journal of Experimental Social Psychology, 22(5), 453-474. 
Akhavan, P., Hosseini, S. M., Abbasi, M., \& Manteghi, M. (2015). Knowledge-sharing determinants, behaviors, and innovative work behaviors: An integrated theoretical view and empirical examination. Aslib Journal of Information Management, 67(5), 562-591.

Allen, N. J., \& Meyer, J. P. (1990). The measurement and antecedents of affective, continuance and normative commitment to the organization. Journal of Occupational Psychology, 63, 1-18.

Bagozzi, R. P., Yi, Y., \& Phillips, L. W. (1991). Assessing construct validity in organizational research. Administrative Science Quarterly, 36(3), 421-458.

Bassani, C. (2007). Five dimensions of social capital theory as they pertain to youth studies. Journal of Youth Studies, 10, 17-34.

Bhagwatwar, A., Hara, N., \& Ynalvez, M. A. (2013). Out of Asia: Understanding the nexus between technology usage and research productivity in Japan, Singapore, and Taiwan. International Journal of Information Management, 33(6), 963-970.

Bock, G.-W., Zmud, R. W., Kim, Y., \& Lee, J.-N. (2005). Behavioral intention formation in knowledge sharing: Examining the roles of extrinsic motivators, socialpsychological forces, and organizational climate. MIS Quarterly, 29(1), 87-111.

Boulesteix, A.-L., \& Strimmer, K. (2006). Partial least squares: A versatile tool for the analysis of high-dimensional genomic data. Briefings in Bioinformatics, 8(1), 32-44.

Chin, W. W. (2010). How to write up and report PLS analyses. In V. E. Vinzi, W. W. Chin, J. Henseler, \& H. Wang (Eds.), Handbook of partial least squares: Concepts, methods and applications in marketing and related fields (pp. 655-690). Berlin: Springer.

Chong, C. W., Yuen, Y. Y., \& Gan, G. C. (2014). Knowledge sharing of academic staff: A comparison between private and public universities in Malaysia. Library Review, 63(3), 203-223.

Chow, W. S., \& Chan, L. S. (2008). Social network, social trust and shared goals in organizational knowledge sharing. Information \& Management, 45(7), 458-465.

Chudgar, A., Chandra, M., \& Razzaque, A. (2014). Alternative forms of teacher hiring in developing countries and its implications: A review of literature. Teaching and Teacher Education, 37, 150-161.

Cox, E. P. (1980). The optimal number of response alternatives for a scale: A review. Journal of Marketing Research, 17(4), 407-422.

Donate, M. J., \& de Pablo, J. D. S. (2015). The role of knowledge-oriented leadership in knowledge management practices and innovation. Journal of Business Research, 68(2), 360-370.

Finstad, K. (2010). Response interpolation and scale sensitivity: Evidence against 5-point scales. Journal of Usability Studies, 5(3), 104-110.

Fornell, C., \& Larcker, D. F. (1981). Evaluating structural equation models with unobservable variables and measurement error. Journal of Marketing Research, 18, $39-50$.

Fullwood, R., Rowley, J., \& Delbridge, R. (2013). Knowledge sharing amongst academics in UK universities. Journal of Knowledge Management, 17(1), 123-136.

Gefen, D., Straub, D. W., \& Boudreau, M.-C. (2000). Structural equation modeling and regression: Guidelines for research practice. Communications of the Association for Information System, 4: 7.

Goh, S. K., \& Sandhu, M. S. (2013). Knowledge sharing among Malaysian academics: Influence of affective commitment and trust. Electronic Journal of Knowledge Management, 11(1), 38-48.

Hair Jr, J. F., Sarstedt, M., Hopkins, L., \& Kuppelwieser, V. G. (2014). Partial least squares structural equation modeling (PLS-SEM): An emerging tool in business research. European Business Review, 26(2), 106-121. 
Hertzog, M. A. (2008). Considerations in determining sample size for pilot studies. Research in Nursing \& Health, 31(2), 180-191

Hussein, A. T. T., Singh, S. K., Farouk, S., \& Sohal, A. S. (2016). Knowledge sharing enablers, processes and firm innovation capability. Journal of Workplace Learning, 28(8) 484-495

Joiner, T. A., \& Bakalis, S. (2006). The antecedents of organizational commitment: The case of Australian casual academics. International Journal of Educational Management, 20(6), 439-452.

Jolaee, A., Md Nor, K., Khani, N., \& Md Yusoff, R. (2014). Factors affecting knowledge sharing intention among academic staff. International Journal of Educational Management, 28(4), 413-431.

Kang, Y.-J., Kim, S.-E., \& Chang, G.-W. (2008). The impact of knowledge sharing on work performance: An empirical analysis of the public employees' perceptions in South Korea. International Journal of Public Administration, 31(14), 1548-1568.

Kim, S., \& Ju, B. (2008). An analysis of faculty perceptions: Attitudes toward knowledge sharing and collaboration in an academic institution. Library \& Information Science Research, 30(4), 282-290.

Kim, S., \& Lee, H. (2006). The impact of organizational context and information technology on employee knowledge-sharing capabilities. Public Administration Review, 66(3), 370-385.

Lacy, F. J., \& Sheehan, B. A. (1997). Job satisfaction among academic staff: An international perspective. Higher Education, 34(3), 305-322.

Lai, H. M., Chen, C.-P., \& Chang, Y.-F. (2014). Determinants of knowledge seeking in professional virtual communities. Behaviour \& Information Technology, 33(5), 522535.

Lin, H.-F. (2007). Knowledge sharing and firm innovation capability: An empirical study. International Journal of Manpower, 28(3/4), 315-332.

Manstead, A. S. R., \& Van Eekelen, S. A. M. (1998). Distinguishing between perceived behavioral control and self-efficacy in the domain of academic achievement intentions and behaviors. Journal of Applied Social Psychology, 28(15), 1375-1392.

Mcallister, D. J. (1995). Affect- and cognition-based trust as foundations for interpersonal cooperation in organizations. Academy of Management Executive, 38(1), 24-59.

Meyer, J. P., \& Parfyonova, N. M. (2010). Normative commitment in the workplace: A theoretical analysis and re-conceptualization. Human Resource Management Review, 20(4), 283-294.

Nicolas, R. (2004). Knowledge management impacts on decision making process. Journal of Knowledge Management, 8, 20-31.

Osatuyi, B. (2013). Information sharing on social media sites. Computers in Human Behavior, 29(6), 2622-2631.

Putnam, R. D. (1995). Tuning in, tuning out: The strange disappearance of social capital in America. PS: Political Science and Politics, 28(4), 664-683.

Ramayah, T., Yeap, J. A. L., \& Ignatius, J. (2013). An empirical inquiry on knowledge sharing among academicians in higher learning institutions. Minerva, 51(2), 131-154.

Roberto, A. J., Shafer, M. S., \& Marmo, J. (2014). Predicting substance-abuse treatment providers' communication with clients about medication assisted treatment: A test of the theories of reasoned action and planned behaviour. Journal of Substance Abuse Treatment, 47(5), 307-313.

Suhaimee, S., Zaki, A., Bakar, A., \& Alias, R. A. (2006). Knowledge sharing culture in Malaysian public institution of higher education: An overview. In Proceedings of the Postgraduate Annual Research Seminar (pp. 354-359). Skudai, Malaysia: Universiti 
Teknologi Malaysia.

Sveiby, K. E., \& Simons, R. (2002). Collaborative climate and effectiveness of knowledge work - An empirical study. Journal of Knowledge Management, 6(5), $420-433$.

Tan, C. N.-L., \& Md. Noor, S. (2013). Knowledge management enablers, knowledge sharing and research collaboration: A study of knowledge management at research universities in Malaysia. Asian Journal of Technology Innovation, 21(2), 251-276.

Thong, J. Y. L., Hong, W., \& Tam, K. Y. (2002). Understanding user acceptance of digital libraries: What are the roles of interface characteristics, organizational context, and individual differences? International Journal of Human-Computer Studies, 57(3), 215-242.

Voorhees, C. M., Brady, M. K., Calantone, R., \& Ramirez, E. (2016). Discriminant validity testing in marketing: An analysis, causes for concern, and proposed remedies. Journal of the Academy of Marketing Science, 44(1), 119-134

Wang, S., \& Noe, R. A. (2010). Knowledge sharing: A review and directions for future research. Human Resource Management Review, 20(2), 115-131.

Wu, I.-L., \& Chen, J.-L. (2005). An extension of trust and TAM model with TPB in the initial adoption of on-line tax: An empirical study. International Journal of HumanComputer Studies, 62(6), 784-808.

$\mathrm{Yu}$, T. K., Lu, L. C., \& Liu, T. F. (2010). Exploring factors that influence knowledge sharing behavior via weblogs. Computers in Human Behavior, 26(1), 32-41. 